\title{
The construction and practice of computer network course driven by innovative thinking
}

\author{
Shan Zhou ${ }^{1}$, Longxin Lin ${ }^{1, *}$, Yan $\mathrm{Shu}^{2}$, and Nian Xiong ${ }^{1}$ \\ ${ }^{1}$ College of Information Science and Technology, Jinan University, Guangzhou, China \\ ${ }^{2}$ School of Economy and Management, Guangzhou University of Traditional Chinese Medicine, \\ Guangzhou, China
}

\begin{abstract}
Keywords: Innovative thinking, MOOC, SPOC, Computer networks, Flipped classroom.

Abstract. In view of the problems existing in the current teaching of computer network technology and application course, this paper introduces the educational concept driven by innovative thinking into the teaching of the course, and puts forward specific teaching reform measures: the teaching method which adopts the engineering application of innovative thinking as the guidance and focuses the problems on the core knowledge points, combining MOOC, SPOC and flipped classroom teaching philosophy, it is student-centered and arouses students' interest in learning. Practice has proved that the teaching reform has obvious practical effects: students can quickly grasp the basic theory of computer network with more goals, and meanwhile, their practical ability, teamwork ability and innovation ability can be better trained and improved, which is conducive to the cultivation of high-quality innovative talents.
\end{abstract}

\section{Introduction}

In Jinan University, "computer network technology and application" is an elective course of computer advanced course group for the whole university. It aims to popularize network knowledge to the undergraduates of the whole university, so as to stimulate their Internet innovation and entrepreneurship activities. However, due to the inherent characteristics of computer network technology, such as interdisciplinary (the combination of mathematics, physics and electronic technology), strong technicality and high complexity, there is a big gap between the teaching effect and the expectation since its inception. The reasons are as follows:

(1) The traditional teaching method of the course is inefficient. In the teaching process, although teachers adopt a "top-down" teaching method to greatly reduce the difficulty of the course, they still need to spend a lot of time on technical concept explanation, leaving

\footnotetext{
${ }^{*}$ Corresponding author: tzhoushan@jnu.edu.cn
} 
insufficient time for discussion and analysis of innovative network services and business models.

(2) The driving force of traditional teaching methods in cultivating students to form innovative thinking is insufficient. The complexity of computer network course content is high, so the traditional teaching method is to stimulate students' learning by starting with the course. Students are encouraged to form innovative thinking on the Internet and even have innovative activities on the Internet. Such "positive thinking" has little effect in the actual teaching process.

In view of the above problems, We reform course from an innovation-driven perspective [1]: starting from the innovative goal, we constructed the teaching method and content of the computer network general education course in the way of "reverse thinking" and "goal driven", and adopted the efficient teaching process to help students straighten out and build the technical route to achieve the goal. It will lay a solid foundation for students to carry out Internet-based innovation and entrepreneurship activities in the future.

\section{Core concepts of computer network teaching driven by innovative thinking}

For the problems existing in the current computer network course teaching, focusing on the personnel training mode with innovative thinking, this paper makes innovative research and exploration on the teaching-learning -evaluation of computer network course, and determines the following teaching core concepts.

\subsection{Engineering projects driven by innovative thinking are oriented}

The characteristics of "computer network" course can be summarized as follows: 1. Many concepts and complex theories; 2. Wide application and strong practicality; 3. Rapid technology update. The final innovation goal of curriculum learning is to help students to integrate all knowledge points learned, design and build an innovative application based on computer network, and design and build such a system often needs to form a team to complete.

In order to improve students' professional skills, understand the essence of computer network, be able to take the target orientation, make them actively learn and use basic knowledge to analyze and solve the target problems, and at the same time cultivate their team cooperation ability and innovation ability, this course conceives and designs several specific engineering projects according to the teaching content and the actual situation of students. And the project will run through all aspects of the whole teaching activities, while mastering the basic theory, further improve the engineering practice ability and innovation ability of students.

In teaching activities, the actual engineering project is the carrier of teaching. Teachers organize and guide students to conduct research on relevant contents based on their autonomous and exploratory learning. There are various forms for students to investigate, including through network to inquire the development trend, through the library to consult the materials, to the electronic market field survey equipment and materials, to the network center, the library information center or the experimental center and other places to visit network construction, application and so on.

In the form of group cooperation, students are divided into groups according to the complete process of actual work, and discuss and study collaboratively based on the conception, design and implementation of their respective engineering projects, so as to 
achieve the innovative application, consolidation and further exploration of the knowledge they have learned. Finally, students are evaluated by the situation of joint project completion.

\subsection{Problem driven learning of course knowledge points}

The knowledge of computer network is much, the theory is complex, and the students are easy to feel boring. In order to cultivate students' interest in the course, improve the teaching effect and cultivate students' ability to think, analyze and solve problems, this paper tries to apply the problem-driven learning method in classroom teaching by combining with innovative engineering projects.

Through the extraction of the teaching content, the knowledge points of the course are integrated into the form of problems. In the process of teaching, the knowledge points are summarized into problems, and the students are guided to analyze and solve the problems. In the process of solving the problems, the knowledge points are implanted into the students to deepen their understanding of the knowledge points. For example, an introduction to the transport layer might begin with the question driver: "in the course of using the network, are two hosts communicating?" In fact, it is not clear enough. Just think: when we are using the network, in addition to the two hosts must be connected to each other, what else do we need? Step by step, let students know that the entity that is actually communicating is the process in the host. Therefore, protocols used for communication processes must take these factors into account. In this way, students pay attention to the problems mentioned and the solutions introduced until they find a way to solve all the problems thoroughly and gain the most important understanding of the knowledge points. Take advantage of this approach to teaching can active classroom atmosphere, to cultivate students' ability of active thinking and to use knowledge to solve the problem, let the students to deeply understand and grasp the learned knowledge, and guide students to explore in the process and the extension of knowledge and its application, outside the classroom for students to provide innovative space, let its in the mastery of basic knowledge and enhance the ability of innovative thinking and innovative practice.

\subsection{Innovative teaching methods}

Innovative thinking method will be integrated into the assessment of teaching quality, so talent training better meet the needs of social development [6]. Combined with the teaching practice and students' professional background, the traditional single assessment method of courses was changed, and more innovative indicators were extracted to assess students' mastery of curriculum creation knowledge and completion of innovation goals [7].

During the course development, students' innovation goals are assessed in stages, including the mastery of the knowledge points of the course in this stage and the achievement of the innovation goals in stages. The teacher organizes the answer meeting, listens to the student stage achievement report. Students' learning conditions are assessed from the aspects of completion progress of students' innovation goals, professional knowledge accumulation, practical ability, teamwork and communication skills, and innovation ability.

\section{The content and process design of computer network course driven by innovative thinking}

Based on the above innovative thinking driven computer network course teaching concept, the following design is made for the teaching content and teaching process of computer 
network technology and application.

\subsection{Teaching process design}

According to the characteristics of this course and the MOOC, SPOC and flipped classroom teaching concepts, the course teaching process as shown in figure 1 is adopted.

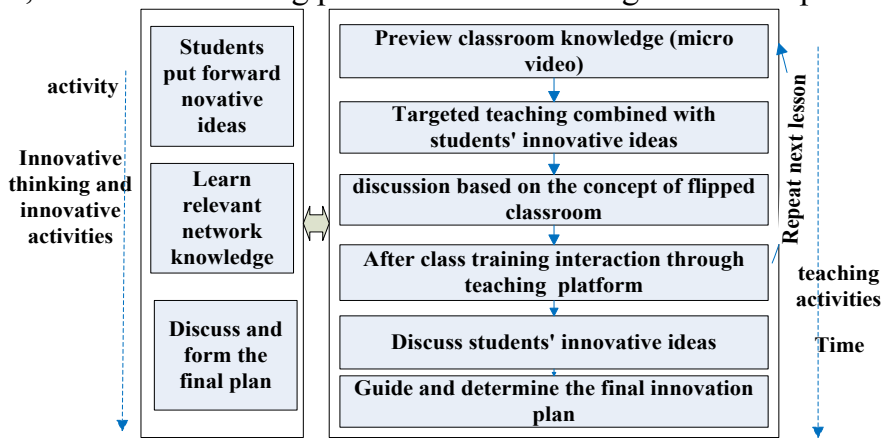

Fig. 1. Process design of computer network course.

In the early stage of the learning process, students will form innovative ideas as soon as possible based on their own life experience, preliminary understanding of the course and their interests. For innovative ideas put forward by students, teachers should carefully analyze all ideas before teaching, extract knowledge points involved in the ideas, carefully prepare knowledge points to explain video (each video is less than 20 minutes, self-produced or assembled) and other relevant materials, and require students to preview before class. In class, the teacher quickly explains all knowledge points, leaving more time for student-led training, discussion and other interactive ways to achieve the purpose of understanding knowledge points in class; After class, students and teachers, and students and students use the course online platform to continue the discussion after class, consolidate the knowledge points; In the teaching activities, one third of the class time is left to discuss the technical implementation of innovative ideas with students, and to guide the determination of the final innovative scheme for subsequent innovation competitions, innovation training projects or future entrepreneurial activities.

\subsection{Teaching micro-video design}

Because this course is a public elective course for the whole school, most of the students who take the courses have only a very weak background in the fields of computer and communication. For this reason, we adopt the teaching concept of MOOC + SPOC, and record a large number of teaching micro-video for all students' innovative ideas involving core knowledge points. Each micro-video lasts for a short time, usually 5-10 minutes. Micro-video tries to be concise and comprehensive. By publishing the core knowledge of the course in the form of micro-video on the online MOOC platform, students can deepen their understanding of the course content in a continuous and repeated way anytime and anywhere.

\subsection{Construction of teaching MOOC platform}

The MOOC or SPOC platforms based on micro videos are suitable for MOOC education. In recent years, open source and free MOOC platforms have emerged at home and abroad. In the spirit of "don't reinvent the wheel", we chose the existing MOOC platform as the teaching 
MOOC platform for this course reform. This teaching reform, we early use based on Moodle built their own way, later the accumulation of micro video content moved to play course network to carry out teaching activities.

\section{The teaching reform of computer network course driven by innovative thinking}

\subsection{New teaching mode based on the combination of innovative thinking driving and flipped classroom thinking}

In the teaching driven by innovative thinking, students' innovative thinking derived from life experience should be put in a core position. Adopt the "goal oriented" method to gradually develop the study and discussion of the required knowledge points. In the process of learning, the teaching concept of "flipped classroom" is borrowed synchronously. Compared with the traditional teaching model, the flipped classroom teaching model is different in the following aspects.

Change of the roles of teachers and students: teachers are no longer traditional classroom knowledge imparts, but as the organizer of the classroom, guide students to carry out communication and discussion in class to complete the digestion and absorption of knowledge. Students from the traditional classroom passive listeners into the classroom exchange and discussion of the main body. According to the specific situation of students' classroom discussion and problem solving, teachers will sort out the key and difficult points of the course or arrange answers to questions to organize classroom teaching.

Arrangement of classroom content: the flipped classroom teaching mode is to reduce the teaching time of teachers in class and increase the time for students to participate in discussion and communication in class. In class, the teaching task is completed through communication and collaboration between students and teachers. By carefully designing the content and topic of class discussion, teachers can maximize and effectively the class time. The course teaching of "computer network technology and application" is integrated with the MOOC concept and the flipped classroom teaching mode to establish the course teaching mode combining the guidance of teachers' key knowledge and students' independent learning.

\subsection{Effect analysis}

In the academic year 2018-2019, the author carried out the practice of teaching reform in two "computer network technology and application" classes opened for the whole school. The effect is mainly reflected in the following points:

The attendance rate and sense of participation of students were significantly improved. After adopting the new teaching method, the attendance rate is close to $90 \%$. In addition, students' sense of participation has been greatly improved, and discussions between teachers and students based on technology and application are frequent.

The quality of course papers submitted by students has been significantly improved. The topics of the course paper mainly focus on the following three categories: discussion on the innovative application of Internet based on students' own professional field; In-depth analysis of existing innovative applications; Research on innovative application prototype based on Internet.

Through extensive communication with students, the main reasons for the obvious improvement of teaching effect are as follows: 
In the process of teaching, the students will be given the leadership of learning in class and after class, so they will be more active. At the same time, it can better cultivate students' communicative and cooperative and thinking ability.

Based on the teaching model driven by innovative thinking, students are encouraged to actively start from their own side and familiar fields, find goals, and make students more interested in the course and better ensure continuity.

\section{Summary}

Driven by innovative thinking, it absorbs the concepts of MOOC, SPOC and flipped classroom, establishes a teaching model that combines teachers' key knowledge teaching with students' independent learning reorganizes and optimizes the course knowledge system, and carefully designs the course content and makes microlectures. Through the three-dimensional construction of "computer network technology and application", curriculum teaching mode should be reformed to give full play to the leading role of teachers and the main role of students, stimulate students' interest in learning, arouse students' autonomy and enthusiasm in learning, so as to better cultivate students' innovative ability.

This paper is partially supported by the following funding: "Reform and Practice of College Computer Fundamentals Using Data as the Mainline", Guangdong Provincial Higher Education Teaching Research and Reform Project, 2017; The teaching research and practice of computer courses for non-computer majors in the fragmented era", Higher Education Teaching Reform Project of Guangdong Province, 2016; "A study on the innovation of the course system of trade major in medical colleges and Universities under the background of Guangdong, Hong Kong and Macao From the perspective of empowerment theory" (2019-152). The corresponding author is Longxin Lin.

\section{References}

1 N. Genco, K. Holtta-Otto, and C. C. Seepersad, "An experimental investigation of the innovation capabilities of engineering students," in Proceedings of the 2014 American Society of Engineering Education Annual Conference, 2014.

2 Yue Wu, Xiaohua Wu, Jia Chen, Xuejun Zhao, "Exploration of MOOC+SPOC Mixed Teaching Modein College Computer Foundation Course, " The 13th International Conference on Computer Science \& Education (ICCSE 2018), p577-579, September 19, 2018.

3 Tong Li, Qiaojie Wang ,Kai Xie," Application of the SPOC Mixed Teaching Mode inthe Post-MOOC Period" 2018 13th International Conference on Computer Science \& Education (ICCSE), p358-361, 8-11 Aug. 2018.

4 Songhua Xie, Lili Fan, Wei Wu. Teaching research of object oriented programming course based on SPOC and project-driven[J]. ICDTE 2018:P53-57.

5 Zhang Li-Hui, Li Fei. Application of SPOC teaching model in courses of computer network in the Post-MOOC period[J]. The 8th International Conference on Information Technology in Medicine and Education, ITME 2016.P436-440.

6 Y. Zhang, R. Liang, and H. Ma, Teaching innovation in computer network course for undergraduate students with packet tracer, IERI.

7 J. Menold, K. Jablokow, S. Purzer, D. M. Ferguson, and M. W. Ohland, "A critical review of measures if innovativeness," in Proceedings of the 2014 American Society of Engineering Education Annual Conference. 